\title{
HEAT TREATMENT OF THIN SHEETS, RESEARCH METHODOLOGY TO DESIGN A COOLING SYSTEM
}

\author{
${ }^{1}$ Milan HNIZDIL, ${ }^{1}$ Martin CHABICOVSKY ${ }^{1}$, Jan KOMINEK \\ ${ }^{1}$ Brno University of technology, Faculty of mechanical engineering, Heat transfer and fluid flow laboratory, \\ Technicka 2896/2, Brno, Czech Republic, EU, milan.hnizdil@vut.cz
}

https://doi.org/10.37904/metal.2020.3477

\begin{abstract}
This paper describes experimental stages of a cooling system designing procedure in laboratory conditions of vertically and horizontally moving surfaces. First stage of the experimental research is focused on a study of a water flow distribution and impact pressure using laboratory equipment and software. Water distribution and impact measurement tests are used for verification of catalogue data provided by nozzle producer so thus an input information to the theoretical water distribution visualization software. Second stage of the experimental research are dynamic tests to describe an influence of several parameters (water flow rate, pressure, nozzle position etc.) on the cooling capability and mainly on the cooling homogeneity. Heat transfer coefficient dependence on a surface temperature and position obtained from these results and used as a boundary condition for simulating real cooling process with real material and thickness. Verification and characterization of the final cooling system could be done using Carousel stand when the linear movement is transferred to a rotation and it enables to simulate very long cooling zones. Examples of the thin sheets cooling and influence of several parameters on the cooling intensity are given in this paper.
\end{abstract}

Keywords: Heat treatment, thin plate cooling, heat transfer coefficient

\section{INTRODUCTION}

Design process of cooling section for sheets cooling is quite complicated due to requirement of high cooling intensity and perfect cooling homogeneity. Very intensive inhomogeneous cooling can lead to plate deformation during product making process [1-4].

Cooling intensity is major important parameter in process control. It could be easily changed by changing parameters that influences a heat transfer coefficient $\left(\mathrm{HTC}\left[\mathrm{Wm}^{-2} \mathrm{~K}^{-1}\right]\right)$. These parameters are: water impingement density, pressure, temperature, strip velocity, spray configuration and so on [5-7]. These parameters have to be characterized deeply for each cooling system. The Heat transfer and fluid flow laboratory (HeatLab) developed testing devices for cooling processes simulations of vertically and horizontally moving plates in laboratory conditions.

Cooling section designing process starts by specification of metallurgists requirements for the new cooling system or by characterization of the current one. Three stages of cooling design follows. First stage is focused on measurements of water spray impact pressure on flat plate. It allows adapting distances between nozzles to control water spray overlaps - cooling homogeneity. When this stage is done the heat transfer tests are performed (second stage). Cooling capability and homogeneity are characterized by heat transfer coefficient dependence on the surface temperature and position of a strip in a cooling zone. These boundary conditions are used for cooling simulation [8]. Simulations results depends also on material properties precision [9] so final cooling design should be experimentally verified (third stage). Full scale cooling zone could be produced. The Carousel stand is used for these tests. It enables to simulate real cooling process in laboratory conditions. Once the cooling regime with real sample is verified, the cooling zone could be easily designed, produced and used in real plant. 


\section{STUDY OF WATER FLOW DISTRIBUTION AND IMPACT PRESSURE (PHASE 1)}

Preliminary design of a cooling zone is dependent on input requirements and HeatLab experiences. Two of the most important parameters are cooling homogeneity and intensity. Thin sheet deformation is very sensitive on a cooling homogeneity especially in a case when very high cooling rates are required [10]. HeatLab developed device for measurement of water impact pressures on flat plate (Figure 1). It is composed of moveable plate equipped by pressure sensor with minimal diameter of $0.1 \mathrm{~mm}$. Device is connected to a computer which records impact pressures and controls movement of the plate under nozzles.

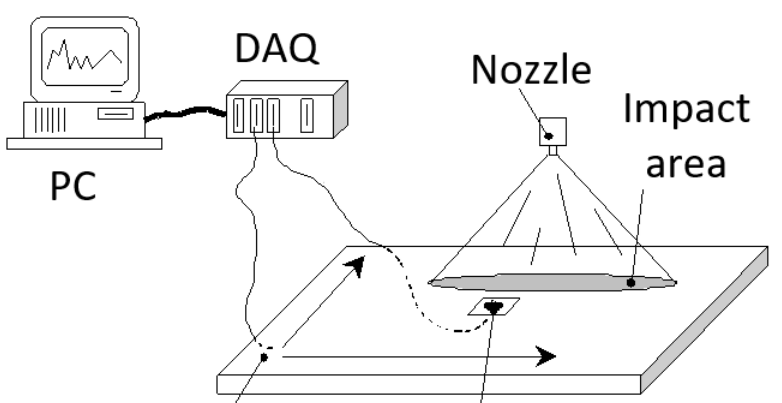

Moving plate Pressure sensor

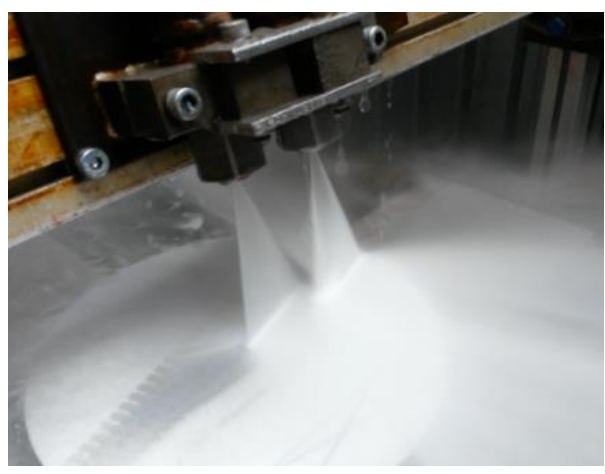

Figure 1 Scheme of the impact pressure measurement device (on the left) and picture with two spraying nozzles during measurement.

Examples of obtained results are shown in Figure 2. The difference between these two tests was only in spraying distance $-50 \mathrm{~mm}$ for results on the left side and $130 \mathrm{~mm}$ on the right side. Water pressure was set to 5 bar. Results show problem of different spay distances which causes cooling non-homogeneities on a strip surface.
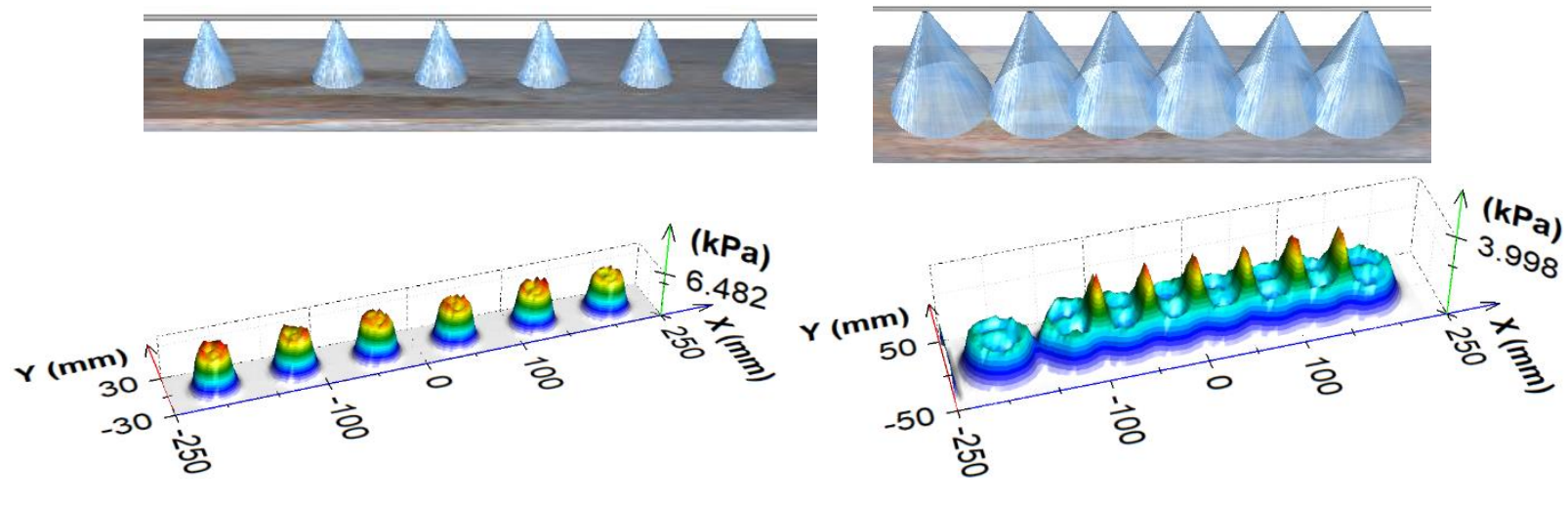

Figure 2 Example of impact pressure measurement results for two non-homogeneous cooling systems with too wide nozzle pitch (on the left) and overlap (on the right)

Several configurations for various nozzles configurations and sizes are tested. Finally, two or three "homogeneous" configurations with different nozzle sizes are chosen for heat transfer tests (Phase 2).

\section{HEAT TRANSFER TESTS (PHASE 2)}

Second stage of a cooling section designing process is focused on heat transfer tests. These tests are done to characterize cooling intensity of preliminary designed system and for verification of a cooling homogeneity. HeatLab developed two experimental devices used for measurement of a heat transfer coefficient on a horizontally (Figure 3 - linear stand) and vertically (Figure 4) moving plates. 
Linear test bench is composed of 7 meters long rotatable girder with a trolley. An experimental plate is made of high temperature resistant austenite stainless steel sheet with maximal thickness of $2 \mathrm{~mm}$. Thermocouples are welded on the rear side of the sheet. This side is insulated. The experimental sheet is surrounded by extended sheet which is not heated during experiment. Dimensions of the sheet are $320 \times 300 \mathrm{~mm}$. Total dimensions with surrounding sheets are $850 \times 550 \mathrm{~mm}$.
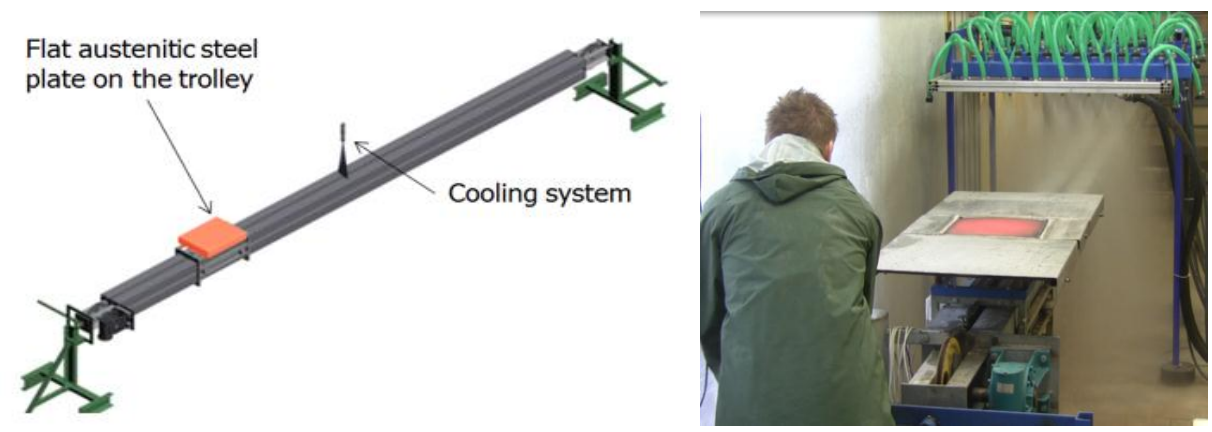

Figure 3 Linear stand scheme (on the left) and picture of running experiment on horizontally moving plate

Vertical stand is similar to the linear stand but the experimental plate is oriented (moving) vertically.

Experiment procedure is similar for both stands. Experimental sheet is heated to the initial temperature in inert atmosphere. The water pump is switched on and a heater is removed. Experimental sheet is then moved with required velocity through a cooling zone reversibly until it is cooled to required temperature (usually lower than $100^{\circ} \mathrm{C}$ ). Maximal movement velocities are $10 \mathrm{~ms}^{-1}$ for linear stand and $5 \mathrm{~ms}^{-1}$ for vertical stand. Temperatures and position information are recorded by data-logger with frequency of $320 \mathrm{~Hz}$. Data are downloaded to a computer and evaluated.
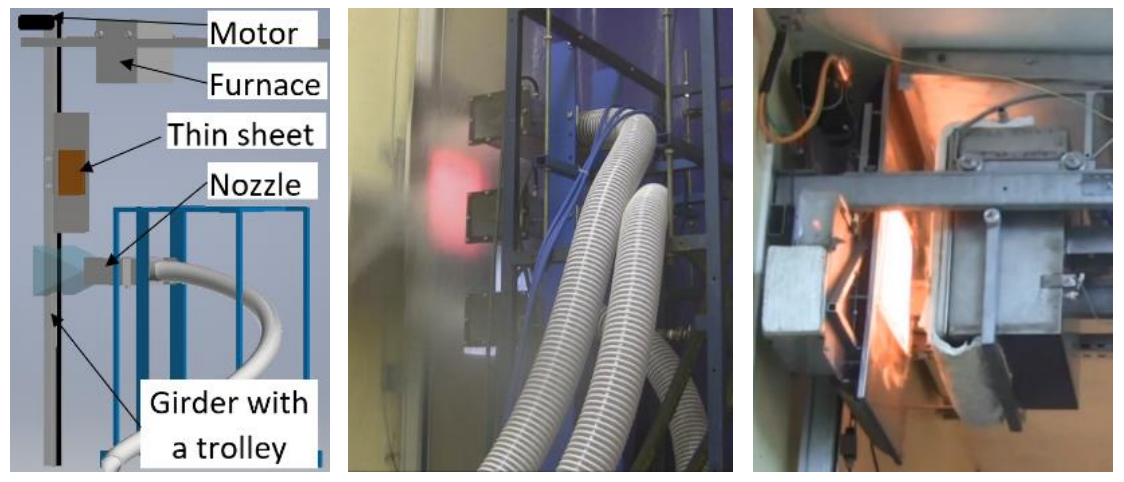

Figure 4 Scheme of the vertical stand (on the left), picture of the experimental sheet in the cooling zone (in the center) and experimental sheet right after heating (on the right)
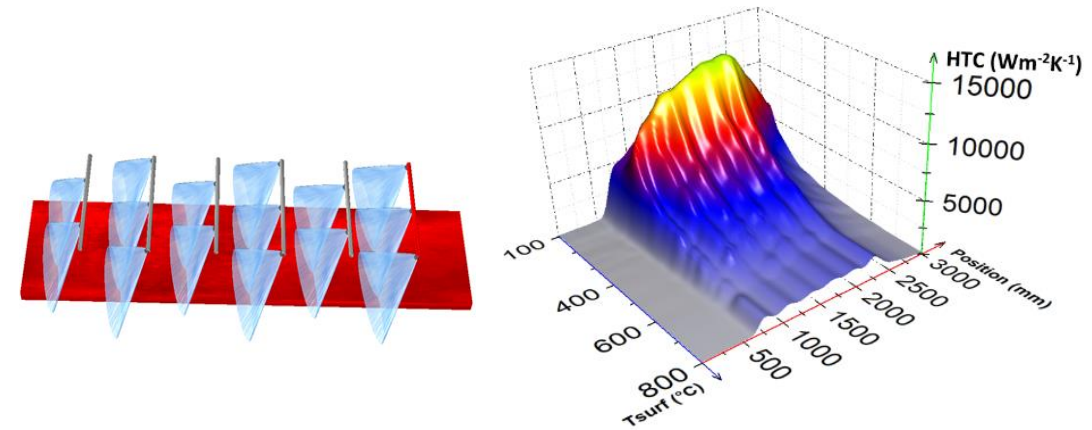

Figure 5 Example of a heat transfer coefficient dependence on the surface temperature and position, $3 \mathrm{D}$ view on the left and top view on the right, cooling zone scheme is on the left side 
Various types of nozzles and configurations (configurations chosen during impact tests), water pressures, movement velocity are examples of tested parameters. Heat transfer coefficient dependence on the position and surface temperature are obtained from these tests using inverse task (Figure 5). Detail information about inverse task could be found in [11-15]. Cooling intensity and homogeneity is evaluated by comparison of obtained heat transfer coefficient dependences on the surface temperature for selected position interval.

Cooling homogeneity comparison examples are shown in Figure 6. Thermal sensors were positioned in line in nozzle axis and between. Heat transfer coefficients are almost identical for homogeneous cooling (on the left). Plate surface was recorded by video camera under the cooling zone. The surface picture after a pass through cooling zone is shown in corresponding graph (Figure 6). Tigers are clearly visible in the right picture where non-homogeneous cooling is presented.
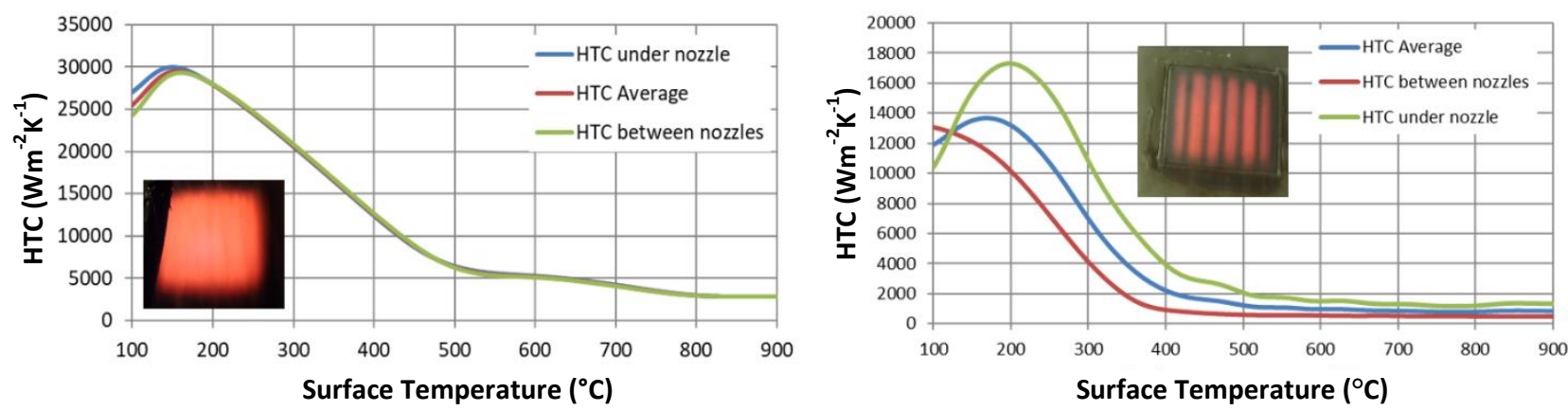

Figure 6 Example of homogeneous (left graph) and non-homogeneous cooling system (right graph) with a corresponding sheet surface picture. Thermocouples were positioned in areas in nozzle axis (under nozzle) and between

Cooling intensity is very important parameter in cooling section development process. Figure 7 and Figure 8 shows influence of several parameters on the cooling intensity - heat transfer coefficient increases with increasing of water pressure (flow rate). It is quite clear. Interesting are results shown in Figure 7 on the right [16]. There were tested various water impact angles (water knife). The highest heat transfer coefficient was found for impact angle of $30^{\circ}$. Other very interesting result is in shift of a Leidenfrost temperature for cooling with different water temperatures (Figure 8 on the left) [17 and 18]. Other parameter could be different surface roughness. Polished, brushed and standard surfaces were tested. The small difference in surface roughness (Ra) did not influence the heat transfer coefficient significantly (Figure 8 on the right). The final design of a cooling zone could be defined.
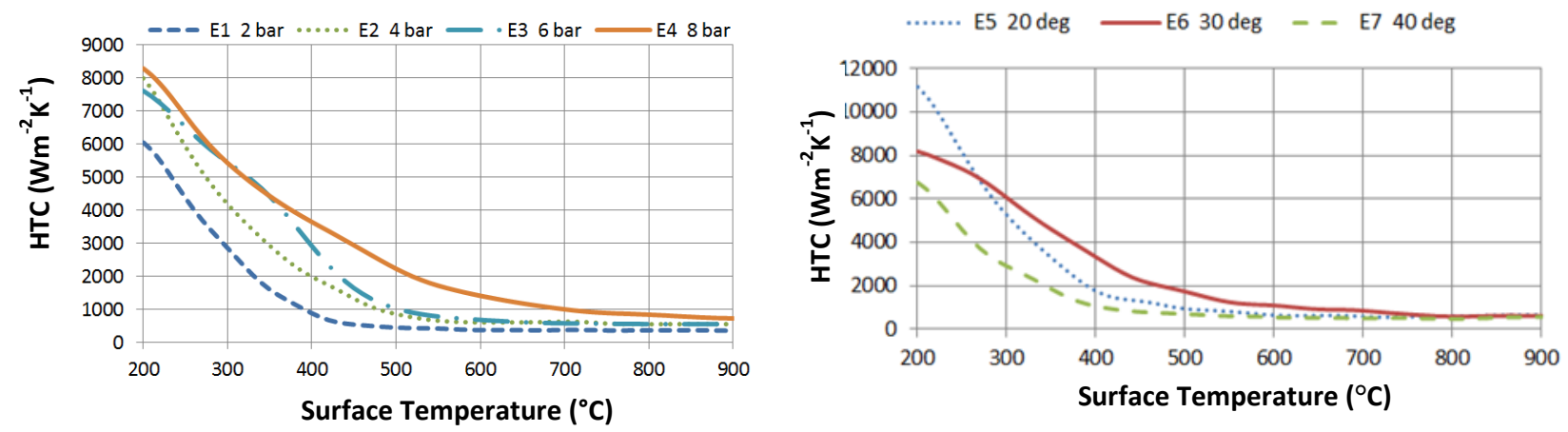

Figure 7 Heat transfer coefficient dependence on the surface temperature, influence of the water pressure on HTC and water impact angle [16] 

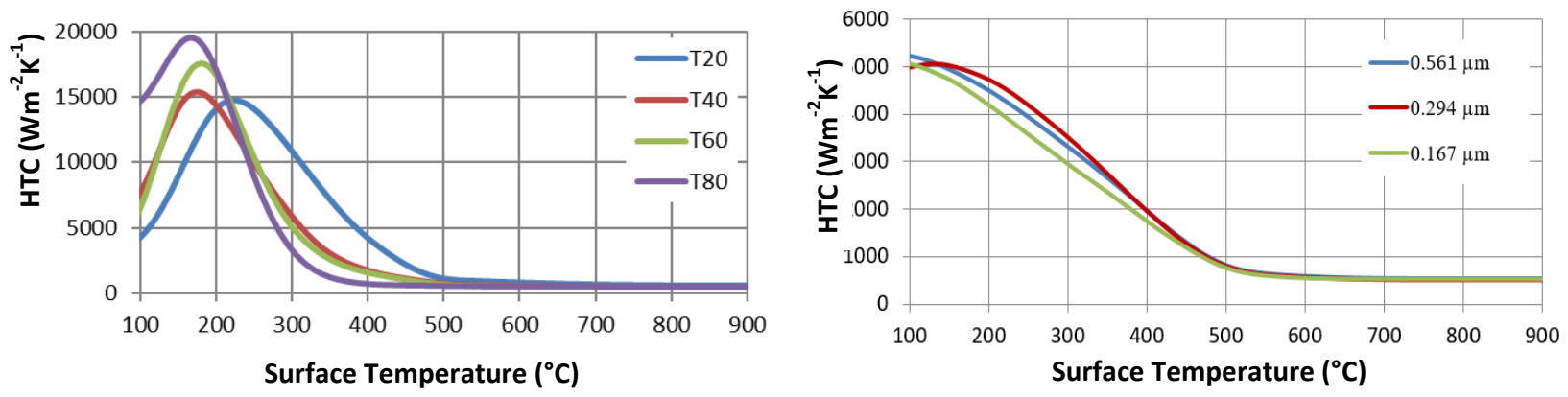

Figure 8 Example of dependence of the water temperature (left picture) [17] and surface roughness (on the right) on the cooling intensity

\section{VERIFICATION OF THE SIMULATIONS IN LABORATORY CONDITIONS (PHASE 3)}

Last stage of this project could be verification of the cooling regime when the cooling length is higher than $2 \mathrm{~m}$. HeatLab developed an experimental device termed Carousel (Figure 9). A linear movement of a real product (in steel mill) is converted to the rotation movement. Testing device is compound of a heater, rotating arm holding the sample, and cooling section, which enables spraying with two different nozzle sizes (hard cooling and soft cooling). An experiment starts with heating of the real material sample to the initial temperature higher than AC3. Then this temperature is hold for required time in inert atmosphere. Afterwards the heater is opened and the sample is moved to the cooling position. The rotation velocity is set. Pneumatically driven deflector is removed and the water sprays on the sample surface. Two nozzle sizes could be used during this experiment. Bigger size nozzles simulating hard cooling and smaller size nozzles simulating soft cooling. Appropriate cooling regime is defined by simulations using boundary conditions obtained in previous phases.
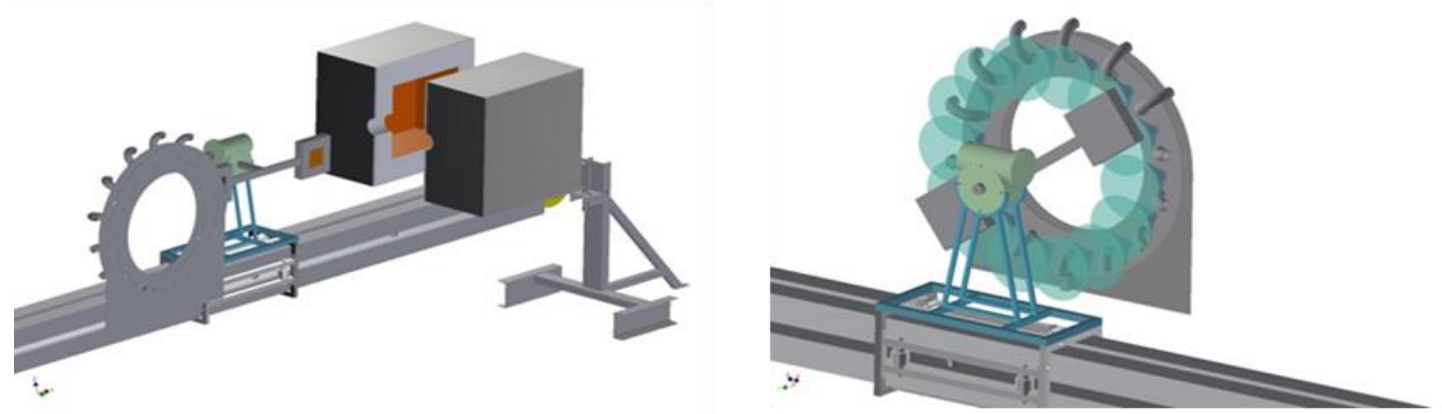

Figure 9 Scheme of Carousel stand
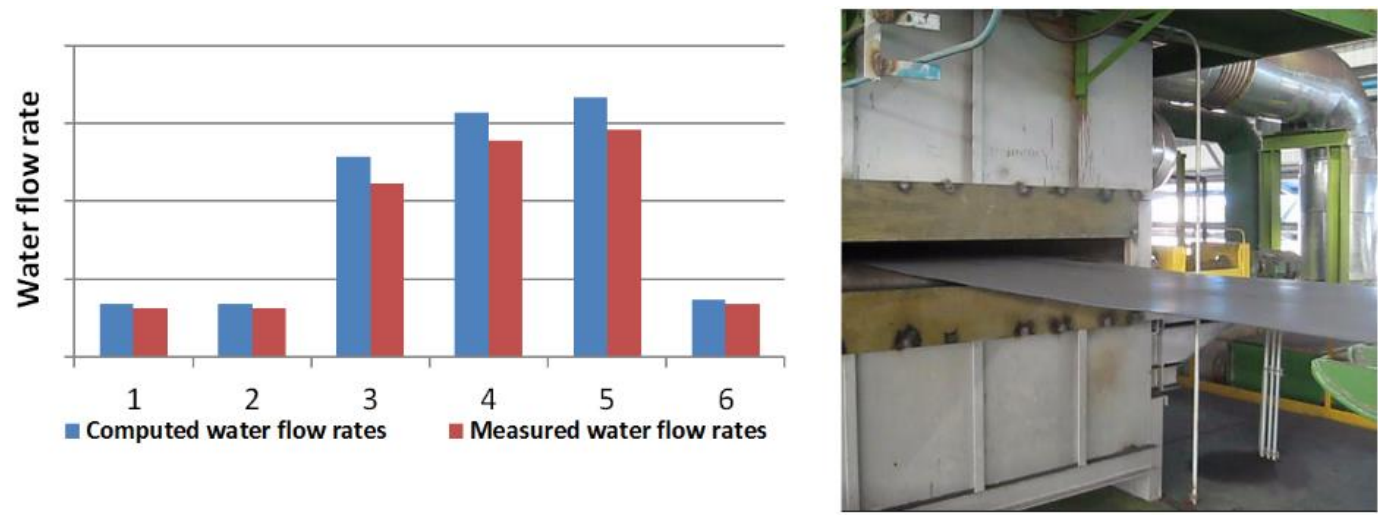

Figure 10 Differences between predicted and measured flow rates which are necessary to cool down the strip for various cooling sections (on the left) and picture of the strip after annealing [19] 
The Fives stein company designed new cooling section for heat treatment of stainless steel sheets [19]. They used boundary conditions (HTC dependence on the surface temperature) to size and produce its cooling section for stainless steel annealing. Fives Stein has made a measurements campaign on an industrial plant to compare laboratory measurements and plant measurements. It appeared that these measurements are in good agreement (Figure 10 - comparison of predicted and needed water flow rate for 6 cooling regimes).

\section{CONCLUSION}

Heat transfer and fluid flow laboratory developed methodology to safely design cooling section which fulfill customer requirements. The methodology is divided to three main phases. This process starts with measurement of nozzles impact pressure for preliminary designed cooling zones. These tests are focused on the cooling homogeneity for various nozzle sizes and arrangement. Several parameters are tested during second phase (water pressure/flow rate, spray distance, nozzle size, water temperature, nozzle configuration etc.) Cooling capability and homogeneity are investigated and final design of a cooling zone could be done. Last stage is focused on verification of the real process. The Carousel stand is used. A linear movement of real product (in steel mill) is converted to the rotation movement. Two cooling regimes could be simulated during one test - hard and soft cooling. Fives Stein built new cooling section of stainless steel sheets in plant mill and they did their own measurements. They were in a good agreement with laboratory measurements.

Results included in this paper (examples) shows interesting conclusions. Impact tests showed sensitivity of the cooling homogeneity on spray distance and nozzle configuration. Heat transfer tests showed quite clear increasing heat transfer coefficient with increasing water pressure. Interesting results was found also for different water temperature when the Leidenfrost temperature decreases with increasing water temperature. Surface roughness did not influenced the cooling intensity but maximal roughness was $\mathrm{Ra}=0.6 \mu \mathrm{m}$.

\section{ACKNOWLEDGEMENTS}

\section{The paper presented has been supported by the internal grant of the Brno University of Technology focused on specific research and development No. FSI-S-20-6478.}

\section{REFERENCES}

[1] KAVICKA F.; DOBROVSKA J., STRANSKY K., SEKANINA B., STETINA J.; MAUDER T., MASARIK M. Breakout of a slab as the result of changes in the thermophysical properties of continuously cast steel. Fatigue \& fracture of engineering materials \& structures. 2014, vol. 37, issue 1, pp 29-38, DOI: 10.1111/ffe.12075.

[2] KOTRBACEK P., RAUDENSKY M.; HORSKY J.; POHANKA M. Experimental study of heat transfer in hot rolling. Revue de metallurgie-cahiers d informations techniques. 2006, vol. 103, issue 7-8, pp. 333-341, DOI: 10.1051/metal:2006134.

[3] RAUDENSKY M., HORSKY J., POHANKA M. Optimal cooling of rolls in hot rolling. Journal of materials processing technology. 2002, vol. 125, pp. 700-705, DOI 10.1016/S0924-0136(02)00310-2.

[4] Mauder T., Stetina J. High Quality Steel Casting by Using Advanced Mathematical Methods. Metals. 2018, vol. 8, issue 12, DOI: 10.3390/met8121019.

[5] H. M. AI-AHMADI, K. KASPERSKI, Experimental study on the spray cooling of high temperature metal using full cone industrial sprays. In 85th Steelmaking conference. NASHVILLE, TN, 2002, vol. 85, pp. 365-374.

[6] F. XU, M. S. GADALA, Heat transfer behavior in the impingement zone under circular water jet. International journal of heat and mass transfer, 2006, vol. 49, p. 3785-3799, DOI: 10.1016/j.ijheatmasstransfer.2006.03.034.

[7] RAUDENSKY, M., BOHACEK, J. Leidenfrost phenomena at hot sprayed surface. In 7th ECI International conference on boiling heat transfer boiling, Florianopolis, Brazil, 2009.

[8] POHANKA, M., KOTRBACEK, P. Design of cooling units for heat treatment. Heat treatment conventional and applications. InTech. Rijeka, Croatia: InTech, 2012, pp. 1-20, ISBN: 978-953-51-0768-2. 
[9] TKADLECKOVA M., MICHALEK K., KLUS P., GRYC K., SIKORA V., KOVAC M. Testing of numerical model settings for simulation of steel ingot casting and solidification. In $20^{\text {th }}$ anniversary international conference on metallurgy and materials. Ostrava: Tanger, 2011, pp. 61-67.

[10] HRABOVSKY J., POHANKA M., LEE PJ., KANG JH. Experimental and numerical study of hot-steel-plate flatness. Materiali in tehnologije. 2016, vol. 50, issue 1, pp. 17-21, DOI: 10.17222/mit.2014.153.

[11] POHANKA, M., ONDROUŠKOVÁ, J. Implicit numerical multidimensional heat-conduction algorithm parallelization and acceleration on a graphics card. Materiali in Tehnologije. 2016, vol. 50, issue 2, pp. 183-187, DOI: 10.17222/mit.2014.128.

[12] CARNOGURSKA M., PRIHODA M., HAJKR Z., PYSZKO R., TOMAN Z. Thermal effects of a high-pressure spray descaling process. Materiali in tehnologije, 2014, vol. 48, issue 3, pp 389-394, ISSN: 1580-2949.

[13] KOMINEK J., POHANKA M. Estimation of the number of forward time steps for the sequential beck approach used for solving inverse heat-conduction problems. Materiali in tehnologije, 2016, vol. 50, issue: 2, pp. 207-210, DOI: 10.17222/mit.2014.192.

[14] ONDROUSKOVA J., POHANKA M., VERVAET B. Heat-flux computation from measured-temperature histories during hot rolling. Materiali in tehnologije, 2013, vol. 47, issue 1, pp. 85-87.

[15] RAUDENSKY M., POHANKA M., HORSKY J. Combined inverse heat conduction method for highly transient processes. Advanced computational methods in heat transfer VII, 2002, vol. 4. pp. 35-42.

[16] HNIZDIL M., CHABICOVSKY M., RAUDENSKY M. Influence of the impact angle and pressure on the spray cooling of vertically moving hot steel surfaces. Materiali in tehnologije. 2015, vol. 49, issue 3, pp. $333-336$ DOI: 10.17222/mit.2013.239.

[17] HNIZDIL M., RAUDENSKY M. Influence of Water Temperature on the Cooling Intensity during Continuous Casting and Hot Rolling. In $21^{\text {st }}$ International conference on metallurgy and materials. Ostrava: Tanger, 2012, pp. 129-134.

[18] POHANKA M., VOTAVOVA H., RAUDENSKY M., HWANG JY., YOU JW., LEE SH. The effect of water temperature on cooling during high pressure water descaling. Thermal Science. 2018, vol. 22, issue 6, pp. 29652971, DOI: 10.2298/TSCI160209163P.

[19] HNIZDIL M., CHABICOVSKY M., RAUDENSKY M., MAGADOUX E., CODE F. Spray cooling unit for heat treatment of stainless steel sheets. Advanced material research. 2014, vol. 936, pp. 1720-1724, ISSN: 16628985, DOI:10.4028/www.scientific.net/AMR.936.1720. 